\title{
The COVID-19 match: what Canadian anesthesia programs can do for the virtual match cycles
}

\author{
Kacper Niburski, MA (D) Pablo Ingelmo, MD, CM • Natalie Buu, MD, \\ CM, FRCPSC
}

Received: 13 December 2020/Revised: 30 January 2021 / Accepted: 1 February 2021/Published online: 18 February 2021

(C) Canadian Anesthesiologists' Society 2021

\section{To the Editor,}

The advent of coronavirus disease (COVID-19) has destabilized medical education in Canada. All visiting anesthesia electives were halted by the Association of Faculties of Medicine of Canada (AFMC) on 11 June 2020. ${ }^{\mathrm{A}}$ Students were limited to their own institutions and its availabilities, which may also be restricted given COVID-19 precautions and limited physical and elective space. Little has been suggested to departments as to how best to engage students for the 2020-2021, and potentially future restricted, match cycles. Previously, a strong performance during a home institution elective was considered the best means of assessment. ${ }^{1}$ This letter discusses the possible methods of increasing exposure of students to non-home programs and a means to provide virtual engagement.

In 2019, the AFMC instituted its Student Elective Diversification Policy (SEDP) that mandated programs to be more transparent with their requirements in selecting applicants. ${ }^{\text {A }}$ Unfortunately, only 11 of 17 anesthesia programs list their breakdown. ${ }^{2}$ Hammoud et al. suggest that providing this information during the COVID-19

\footnotetext{
K. Niburski, MA ( $\bowtie)$

Faculty of Medicine, McGill University, Montreal, QC, Canada

e-mail: kacperniburski@gmail.com

P. Ingelmo, MD, CM

Department of Pediatric Anesthesia, McGill University of Health Center, Montreal, QC, Canada

N. Buu, MD, CM, FRCPSC

Department of Pediatric Anesthesia, McGill University of Health Center, Montreal, QC, Canada
}

McGill Residency Program in Anesthesiology, Montreal, QC, Canada pandemic will not only benefit this current match cycle but also future matches as well. ${ }^{3}$ This information would form fair strict screening criteria to determine who receives interviews, what extracurricular involvement is recommended, and the value of research in the application. It further expands the online presence of the programs to attract future applicants.

The access to such information is largely dependent on the COVID-19 administrative burden. Schools have dealt with the pandemic differently, depending on the regional COVID-19 prevalence. Some schools, such as the University of Manitoba, where prevalence was initially low, managed to maintain an in-person teaching sessions into April; this contrasted with Montreal, initially the hardest hit region, where schools required the quick transition to online-only education. This similarly meant that the availability of electives differed regionally, with some programs' rotations requiring cancellation. Some schools have offered mentorship programs and peermentoring to facilitate substitutes to in-person sessions. ${ }^{4}$

Programs in the US have formally provided immersive, online educational experiences to supplement lost opportunities for students, both at their own institution and at others. ${ }^{4}$ No school in Canada currently offers these types of electives; however, the US experience has shown that there is a need to standardize the availability, content taught, and the number of students who are allowed in any one virtual elective so as to keep teaching valuable.

Questions remain as to how virtual electives would work in a skill-based discipline such as anesthesia. Watching a video of intubation is not the same as performing on a

\footnotetext{
A The Association of Faculties of Medicine of Canada. COVID-19; 2020. Available from URL: https://afmc.ca/en/priorities/covid19 (accessed February 2021).
} 
patient, even in the best simulations. Some aspects of anesthesia, however, such as telemedicine for pain management, may be better suited for educational adaptation. $^{5}$

Virtual show cases have further been suggested as one means for applicants to assess a program and to better understand the culture, the environment, and the workplace practices in residency. For example, the Internal Medicine department at the University of Toronto has offered inteaching online sessions for interested applicants and is in the early stages of setting up a virtual mentorship program to pair interested applicants with mentors. ${ }^{\mathrm{B}}$ Only 12 of the 17 anesthesia programs offer show cases currently. ${ }^{2}$ It is likely, however, that programs will have no choice but to develop this aspect to attract students prior, during, or following the interview process.

Given these suggestions, there is little doubt that the COVID-19 pandemic will have lasting effects on all anesthesia programs. Although impossible to replace hands-on skill and direct clinical and physical encounters, anesthesia programs have a rare opportunity to innovatively expand their online presence and availability.

Disclosures None.

Funding statement None.
Editorial responsibility This submission was handled by Dr. Hilary P. Grocott, former Editor-in-Chief, Canadian Journal of Anesthesia.

\section{References}

1. Niburski K, Li MM, Kouri M, et al. The Association of Faculties of Medicine of Canada electives diversification: a discussion of its implications in anesthesiology. Can J Anesth 2020; DOI: https:// doi.org/10.1007/s12630-020-01750-0.

2. Niburski K, Nguyen DD, Ingelmo P, Buu N. Impact of COVID-19 on Canadian anesthesia resident matching: challenges and opportunities for applicants. Can J Anesth 2020; DOI: https:// doi.org/10.1007/s12630-020-01878-z.

3. Hammoud MM, Standiford T, Carmody JB. Potential implications of COVID-19 for the 2020-2021 residency application cycle. JAMA 2020; DOI: https://doi.org/10.1001/jama.2020.8911.

4. Rastegar Kazerooni A, Ali A, Amini M, Tabari P, Moosavi M. Peer mentoring for medical students during the COVID-19 pandemic via a social media platform. Med Educ 2020; 54: 762-3.

5. Eccleston C, Blyth FM, Dear BF, et al. Managing patients with chronic pain during the COVID-19 outbreak: considerations for the rapid introduction of remotely supported (eHealth) pain management services. Pain 2020; 161: 889-93.

Publisher's Note Springer Nature remains neutral with regard to jurisdictional claims in published maps and institutional affiliations.
B University of Toronto. Chair's Column: Virtual Via Zoom - The New Normal? - May 5 2020. Department of Medicine. Available from URL: https://www.deptmedicine.utoronto.ca/news/chairscolumn-virtual-zoom-new-normal (accessed February 2021). 